\title{
МИРОВОЙ РЫНОК ЭНЕРГЕТИЧЕСКИХ РЕСУРСОВ: АНАЛИЗ ПРОИЗВОДСТВА И СПРОСА НА ЭНЕРГОНОСИТЕЛИ, ПЕРСПЕКТИВЫ СЕКТОРА
}

\author{
Волотковская Наталья Сергеевна \\ Дочент, Северо-Восточный федеральный \\ университет им. М. К. Аммосова, Политехнический \\ институт (филиал) в г. Мирном \\ volotkovska_n@mail.ru \\ Волотковская Юлия Александровна
} OF ENERGY PRODUCTION AND DEMAND, SECTOR PROSPECTS

\author{
N. Volotkovskaya \\ Yu. Volotkovskaya \\ A. Semenov
}

Summary. The paper analyzes the global demand for various energy sources in recent years. A number of works are considered in which by 2040 a double increase in the global energy production market is forecasted. Also, a number of other works predict the transition of energy demand from the US and EU countries to the Asian market. The percentage distribution of global energy needs is provided, provided by six types of resources, among which oil, gas and coal will remain dominant. Some studies have suggested that the demand for natural gas will continue to grow faster than the demand for oil or coal. To confirm or refute this theory, the authors constructed a mathematical model of the dynamics of gas demand in comparison with the total demand for oil and coal, as a result of which two different polynomial functions were obtained with almost the same probability confirming this forecast. The article also noted such important factors as: a decrease in solid fuel production in the UK; steady growth in the importance of renewable energy in the last few years; slowdown in the development of nuclear energy by some key countries; general shortage of energy resources in the EU countries, etc.

Keywords: demand, energy consumption, oil, gas, coal, renewable energy sources, world market, mathematical model.

\section{Введение}

B 21 веке из-за появления новых технологий в производстве происходит количественное и качественное изменение структуры распределения и потребления энергоресурсов. В мировой экономике большинство государств начинают сокращение внукают в промышленный оборот местные виды традиционного топлива и обязательно возобновляемого [1]. В течение 2015-2019 гг. из-за политической нестабильности в мире рост производства основных видов протреннего потребления энергии. Они активно привле- 


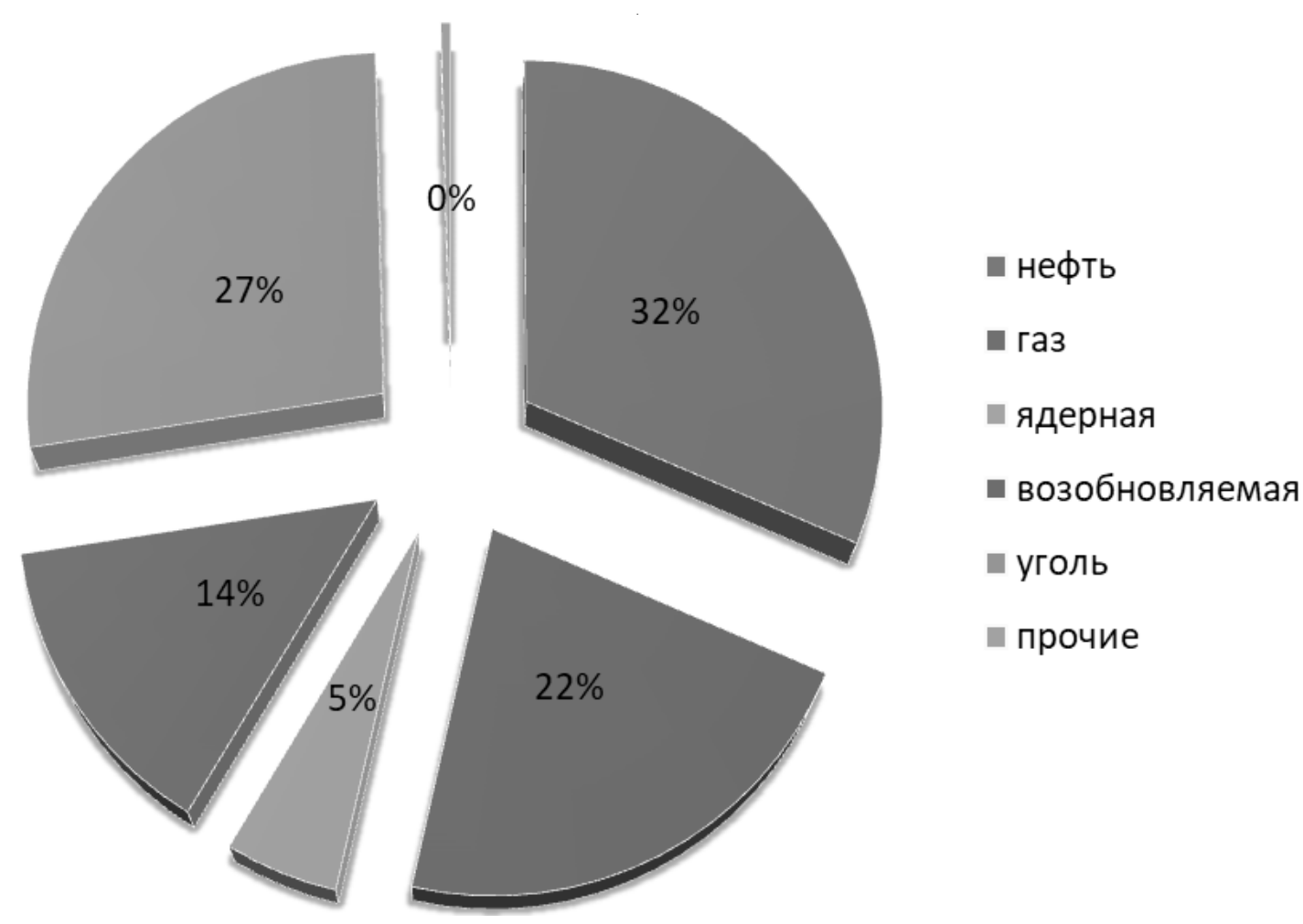

Рис. 1. Мировая потребность (спрос) на разные источники энергии в 2018 году

дукции был относительно скромным в большинстве государств. Кроме того, введение санкций против нашей страны также повлияло на структуру и динамику роста темпов производства [2].

В течение ближайших 20 лет на мировом рынке ожидается, что основной спрос на энергоносители перейдет от США и стран ЕС к азиатским рынкам, которые на данный момент быстро развиваются. Согласно этому ожиданию к 2040 году мировой рынок производства энергии должен без малого удвоиться. Такой прогноз основываются на положительной динамике экономических показателей стран с развивающейся экономикой. В целом они показывают ежегодно трехпроцентный рост и способны в перспективе удвоить эти показатели (при благоприятном сценарии) [3]. Однако эти темпы роста в значительной степени компенсируются повышением эффективности использования энергии. Таким образом, спрос на потребление энергии в целом по миру должен вырасти примерно не на $100 \%$, а только на $30 \%$. При том, что нефть, газ и уголь останутся основными источниками энергии, а новые возобновляемые источники энергии вместе с ядерной и гидроэнергетикой должны будут обеспечить только половину от ожидаемых 30\% энергии. Несмотря на это, традиционные источники энергии (нефть, газ и уголь) останутся доминирующими. Ожидается, что в 2040 году на них придется более 75\% поставок (по сравнению с 81\% в 2018 году) (рис. 1).
В 2018 г. мировые энергетические потребности обеспечивались шестью видами ресурсов. Основу спроса составляли углеводороды (81\%): нефть (32\% суммарного потребления), газ (22\%) и уголь (27\%). Данное сырье, как и раньше, в ближайшие десятилетия останется основой энергообеспечения мирового хозяйства, при этом разведанные запасы нефти и газа при современном уровне добычи будут достаточны в течение ближайших 50 лет, уголь - 150 лет [4].

\section{Результаты исслеАования}

В некоторых научных работах $[5,6]$ встречается мнение, что спрос на природный газ будет в дальнейшем расти быстрее, чем спрос на нефть или уголь. Этому способствует быстрое увеличение объемов добычи сжиженного природного газа, что повышает его доступность по всему миру. При построении математической модели динамики спроса на газ по сравнению с суммарным спросом на нефть и уголь были получены две разные полиноминальные функции почти с одинаковой вероятностью (97,96\% и 99,28\%), подтверждающие данный прогноз к 2040 году. Как видно из рис. 2, даже без данных о последнем падении спроса на нефть (март-апрель 2020 года), который произошел из-за рецессии на рынке нефти, вызванной пандемией Covid-19 в мире, объем спроса на нефть и уголь в 2020 году по построенной математической модели 


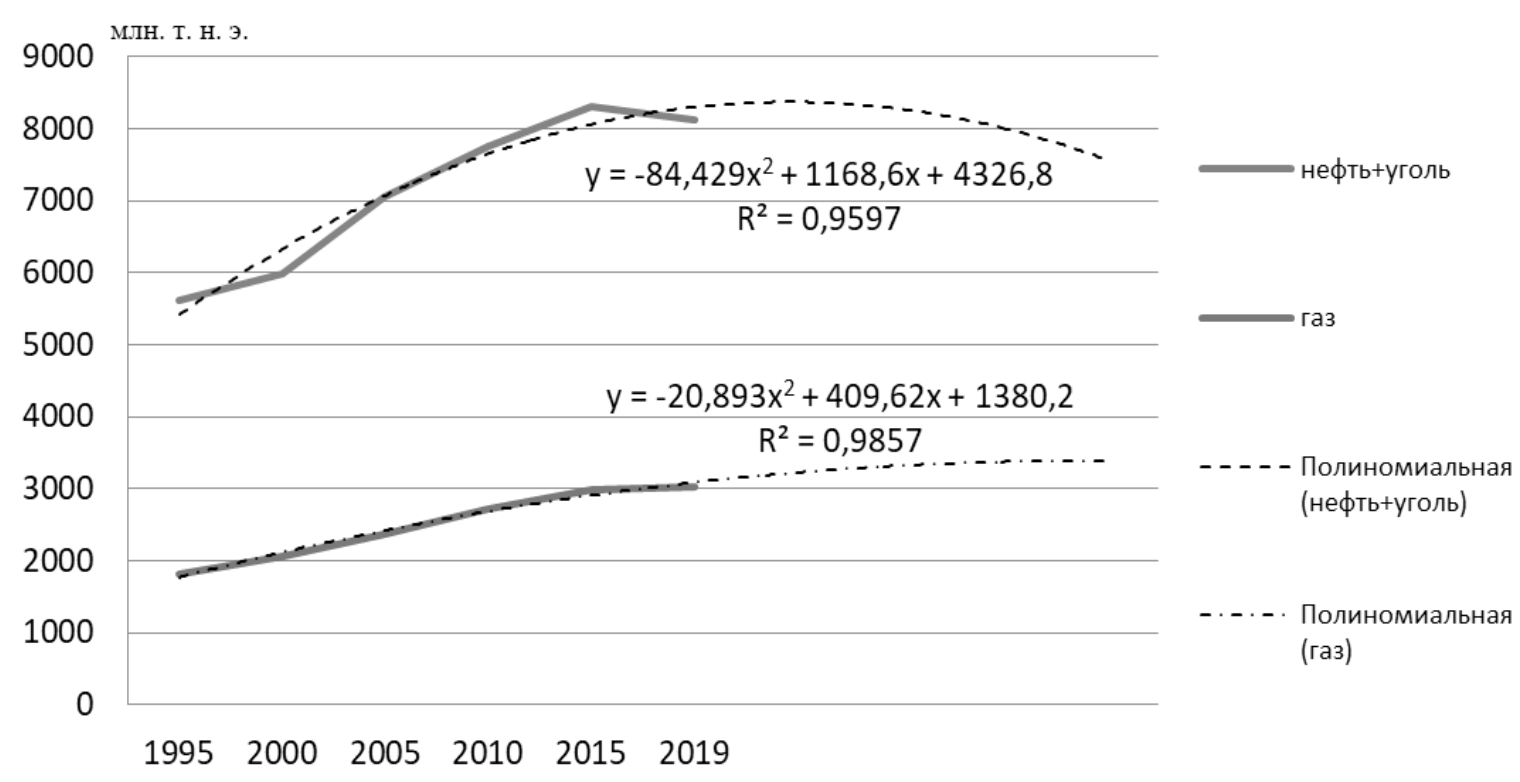

Рис. 2. Прогноз динамики роста спроса на газ по сравнению с суммарным спросом на нефть и уголь

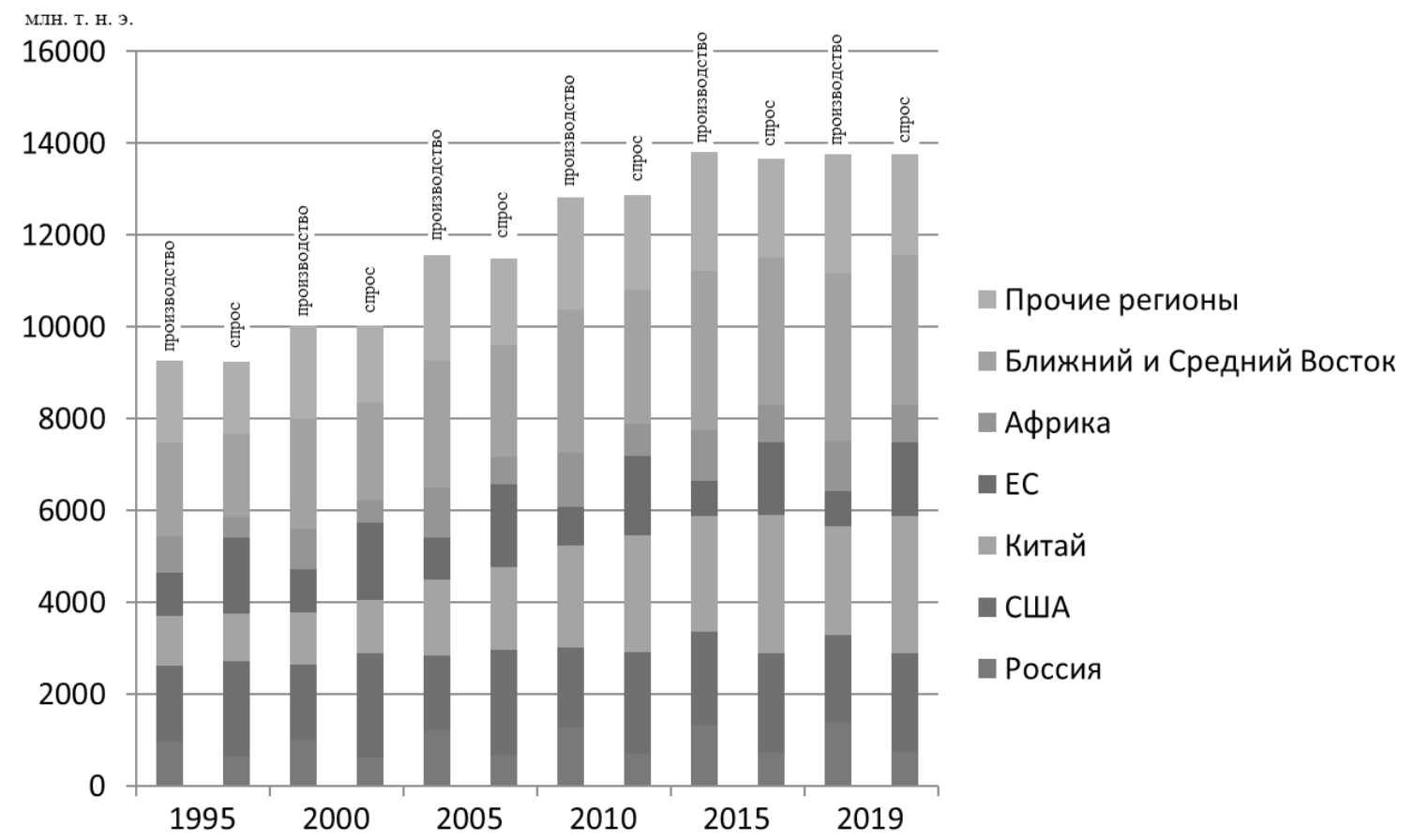

Рис. 3. Динамика производства и изменение глобального спроса на энергоносители по регионам за последние 20 лет

$y=-84,429 \cdot x^{2}+1168,8 \cdot x+4326,8$ должен был остаться на уровне 2019 года без существенного роста. Оценить масштаб нынешнего падения спроса на нефть в пределах всех стран невозможно, если ориентироваться только на колебание спотовых цен барреля нефти. Тем не менее, после выхода из карантина уже в апреле
2020 г. Китай сократил свое потребление нефти на 17\% по сравнению с аналогичным периодом 2019 г.

Динамика производства (предложения) и потребности (спроса) в энергоносителях по отдельным регионам мира приведены на рис. 3. 
Таблица 1. Глобальное производство основных видов энергоресурсов в 1995-2019 гг.

\begin{tabular}{|c|c|c|c|c|c|c|}
\hline \multirow{2}{*}{ Виды энергоресурсов } & \multicolumn{6}{|c|}{ Временной интервал } \\
\hline & 1995 & 2000 & 2005 & 2010 & 2015 & 2019 \\
\hline Уголь & 4996 & 6001 & 7331 & 8660 & 9552 & 9594 \\
\hline Нефть & 1237 & 1212 & 1135 & 974 & 973 & 931 \\
\hline Газ & 2116 & 2747 & 3701 & 4810 & 5552 & 5794 \\
\hline Атомная & 2332 & 2591 & 2768 & 2756 & 2570 & 2606 \\
\hline Возобновляемая & 2636 & 2836 & 3294 & 4200 & 5536 & 5939 \\
\hline в т.Ч. гидро & 2479 & 2618 & 2935 & 3445 & 3905 & 4061 \\
\hline солнечная & 33 & 55 & 141 & 408 & 1132 & 1330 \\
\hline ветряная & 130 & 164 & 226 & 360 & 517 & 571 \\
\hline Другая & 40 & 52 & 58 & 68 & 80 & 82 \\
\hline
\end{tabular}

В 2018-2019 годах добыча нефти увеличилась на 0,5\% за счет стран Ближнего и Среднего Востока при одновременном сокращении объемов добычи данного сырья в Китае и США. В целом последние 10 лет наблюдается рост производства энергоносителей, однако, за счет экономических кризисных колебаний производство энергии в странах ЕС резко сократилось. Их место на рынке заняли страны Ближнего и Среднего Востока. При этом добыча газа увеличилась примерно на 0,5\%, что стало одним из самых низких показателей темпа роста за последние три десятилетия. Некоторое оживление в развитие газового сектора внесла Австралия, которая приступила к эксплуатации новых мощностей по производству сланцевого газа, что способствовало увеличению на 4,8\% объемов межрегиональных поставок этого вида топлива [7].

В структуре энергопотребления экономик развивающихся стран доля углеводородных энергоносителей приблизилась к 12\%, а в развитых капиталистических странах этот показатель находится приблизительно на уровне $20 \%$, учитывая более активное использование атомной энергии и энергии из возобновляемых источников [8].

Рост энергопотребления в развивающихся странах наблюдается в основном при развитии транспортной инфраструктуры и индустриального сектора, а также при улучшении условий жизни населения. В настоящее время на их долю приходится около $60 \%$ глобального спроса.

В ходе кооперации с развитыми государствами, которая происходила с помощью открытия производственных филиалов транснациональных корпораций на территории слабо развитых стран, данная группа стран перенимала современные энергозатратные технологии, переходила на более высокий уровень развития энергетики.

Данные, характеризующие производство и потребление основных видов энергоносителей в мире, представлены в таблице 1.

Так, в последние 10 лет основной прирост глобального спроса на энергоносители обеспечивали Китай, а также Индия и Бразилия (близко 56\%). С 2016 года в суммарном потреблении первичной энергии спрос отмеченных государств превысил 30\% по сравнению с 23\% в 2005 году. Однако, следует заметить, что после стагнации, вызванной в начале 2020 года пандемией короновируса, данная ситуация изменится в сторону уменьшения натуральных показателей с ростом относительных по отношению к таким странам, как США, Россия и страны ЕС. Для сравнения: в США этот показатель вырос на 21,3\% за 15 лет, однако, в глобальном масштабе произошло снижение спроса с 20,2\% в 2005 г. до 15,7\% в 2019 г. от всего мирового потребления энергоносителей.

Отметим также снижение добычи твердого топлива в Великобритании (в 2006 г.- 11,4 млн. т н.э., в 2016 г.2,6 млн. т н.э.) и остановку последних шахт в апреле 2017 г. В итоге, данная отрасль национальной экономики, в прошлом - одна из базовых, - завершила свой более чем 200-летний путь.

В последние несколько лет стабильно растет значимость электрической энергии из возобновляемых источников, выработка которой в 2006-2016 гг. увеличилась на 29\%. Для сравнения: в этот же период производство базовых видов углеводородного топлива увеличивалось 


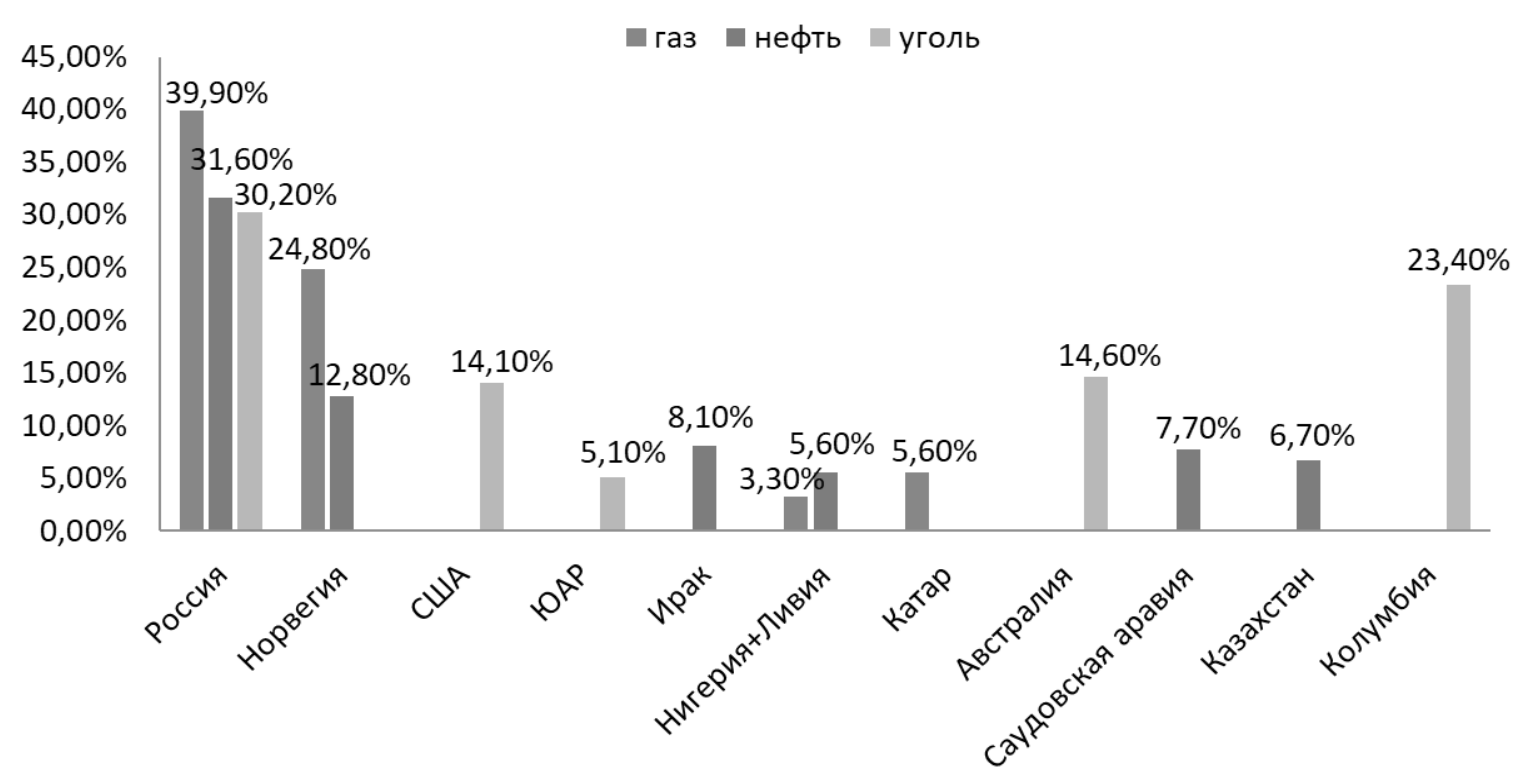

Рис. 4. Структура импорта углеродного топлива в 2016 г в страны ЕС

вдвое меньше - примерно на 15\%. В настоящее время в мире важными источниками генерации являются атомные электростанции и крупные ГЭС (мощностью более 10-25 МВт) $[9,10]$.

Лидерами по масштабам производства атомной энергетики остались США (32,4\% мировой генерации) и Франция $(15,4 \%)$. Германия продолжает придерживаться темпов сокращения атомной энергии.

Япония, которая имела 54 ядерных реактора, остановленных после трагедии на АЭС «Фукусима-1» (март 2011 года), так и не восстановила свои мощности в прежнем масштабе. В 2015 году начался демонтаж блоков, которые находились в эксплуатации более 40 лет. Однако ежегодная закупка угля и газа на 30 млрд. долл. усложнила платежный баланс страны, и в настоящее время наметилось возрождение национальной атомной отрасли (до 2011 г. на ее долю приходилось до 30\% производства электроэнергии). Нарастить выпуск Япония сможет после выполнения комплексных работ по повышению безопасности АЭС в соответствии с требованиями МАГАТЭ.

В глобальном энергетическом хозяйстве наибольший прогресс в развитии был зафиксирован в сфере возобновляемых источников (в 2016 г.- рост на 14,4\%). Лидер сектора - Голландия. В прошлом году на ее долю приходилось около 50\% производимой таким образом энергии, тогда как удельный вес солнечной энергии составил $18 \%$. Тем не менее, страны ЕС испытывают общий дефицит энергоресурсов, который компенсируют за счет импорта из других стран. Основным импортёром при этом остается Россия. Структура импорта приведена на рис. 4. Как видно из этого рисунка, наша страна поставляет в страны ЕС все виды углеродного топлива [11, $12]$.

\section{Зак^ючение}

В целом за последние 20 лет увеличилась эффективность используемых энергоресурсов, снизились энергозатраты. В 2005-2015 гг. при росте мирового ВВП на 26,5\% (в неизменных ценах) глобальное потребление энергии увеличилось лишь на 19\%. В последние годы эффективность использования энергоресурсов увеличилась на фоне снижения потерь потребляемой энергии. В период с 2006 по 2010 гг. при росте мирового ВВП на 26,5\% (в неизменных ценах) мировое потребление энергии увеличилось лишь на 17,8\% [13]. Так в 2006-2010 гг. темпы роста потребления энергоресурсов составили более $2 \%$, и первая половина прошлого десятилетия характеризовалась устойчивым дефицитом энергоресурсов, который составил в среднем 130 млн. тонн.

В период 2011-2015 гг. ситуация начала меняться в обратную сторону. Темпы роста потребления энергии всех видов за последние три года снизились до 1\%, а дефицит изменился в избыток. Так, добыча нефти превысила спрос почти на 90 млн. тонн в год еще в 2018 году, в то время цены на нефть упали примерно в три раза по отношению к рекордным уровням 2008 и 2012 годов [14]. В начале 2020 года перед началом мирового кризиса нетто-экспортеры топливно-энергетических товаров не приняли соответствующих мер по стабилизации рынка, несмотря на очевидные издержки и потери национальных бюджетов, вызванные пандемией короновируса. 


\section{ЛИТЕРАТУРА}

1. Краковская И. Н. Об устойчивой конкурентоспособности, ресурсосбережении и возобновляемой энергетике // Модели, системы, сети в экономике, технике, природе и обществе.-2017. — № 4 (24). - С. 52-64.

2. Клочков В.В. Анализ влияния технологических сдвигов в энергетике на устойчивость российской экономики // Национальные интересы: приоритеты и безопасность. - 2017. - Т. 13.— № 4 (349). — С. 684-698.

3. Иванов А.С., Матвеев И. Е. Мировая энергетика на рубеже 2018 г.: трансформация продолжается, обретая новые оттенки // Бурение и нефть. - 2017.№ 12.- C. 4-13.

4. Костенок И.В., Хоменко Я. В., Ефименко А. В. Современная интерпретация устойчивости нефтегазовых компаний на мировом энергетическом рынке // Вестник Российского экономического университета имени Г. В. Плеханова. — 2020. — № 1 (109). — С. 93-107.

5. Григораш 0.В., Тарасов М. М. 0 необходимости применения возобновляемых источников энергии // Политематический сетевой электронный научный журнал Кубанского государственного аграрного университета. — 2016. — № 118. — C. 949-962.

6. Иванов А.С., Матвеев И. Е. Международная торговля энергоресурсами на рубеже 2018 года // Российский внешнеэкономический вестник.- 2018.№ 1.- C. 17-26.

7. Шаховская Л.С., Попкова Е.Г., Джинджолия А.Ф., Кабанов В.А. «Сланцевая революция»: мифы и реальность // Национальные интересы: приоритеты и безопасность. - 2015. - Т. 11.— № 32 (317). - С. 14-24.

8. Усачёв А. М. Анализ динамики мировой индустрии солнечной энергетики // Интернет-журнал Науковедение. — 2015.— Т. 7.— № 4 (29). — С. 49.

9. Волотковская Н.С., Волотковский А. А., Семёнов А. С., Кинаш А. А. Технико-экономическая оценка программы развития и оптимизации электроэнергетики Республики Саха (Якутия) // Современная наука: актуальные проблемы теории и практики. Серия: Экономика и право.— 2019.— № 6. — С. 14-18.

10. Волотковская Н.С., Семёнов А.С., Федоров 0. В. Анализ структуры и технического состояния западных электрических сетей Республики Саха (Якутия) // Известия высших учебных заведений. Проблемы энергетики.-2018.- Т. 20.- № 11-12.—C. 46-55.

11. Бережнов В. П. Стратегические цели угледобывающих предприятия России в условиях санкций // Экономика: вчера, сегодня, завтра. - 2019. - Т. 9. № 9-1.- С. 368-373.

12. Побирченко В. В. Позиции России в основных сегментах мирового рынка энергоресурсов // Электронный мультидисциплинарный научный журнал с порталом международных научно-практических конференций Интернетнаука. — 2017. - № 1. — C. 43-59.

13. EU energy in figures. Statistical pocketbook 2018 [Электронный ресурс]. Доступно по: https://op.europa.eu/en/publication-detail/-/publication/99fc30ebc06d-11e8-9893-01aa75ed71a1/language-en/format-PDF/source-78277087 (дата обращения: 07.05.2020).

14. Федоров 0.В., Дарьенков А. Б. Энергетическая политика: учебное пособие (2-е издание). — М.: Издательство «КноРус», 2018. — 162 с.

(c) Волотковская Наталья Сергеевна ( volotkovska_n@mail.ru),

Волотковская Юлия Александровна ( kafeiagp@rambler.ru ), Семёнов Александр Сергеевич ( sash-alex@yandex.ru ).

Журнал «Современная наука: актуальные проблемы теории и практики» 